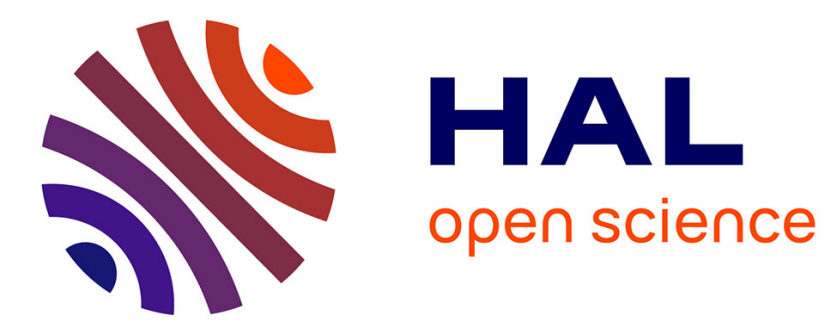

\title{
Public Debt and Economic Geography
}

Federico Trionfetti

\section{To cite this version:}

Federico Trionfetti. Public Debt and Economic Geography. 2012. halshs-00793388

\section{HAL Id: halshs-00793388 \\ https://shs.hal.science/halshs-00793388}

Preprint submitted on 22 Feb 2013

HAL is a multi-disciplinary open access archive for the deposit and dissemination of scientific research documents, whether they are published or not. The documents may come from teaching and research institutions in France or abroad, or from public or private research centers.
L'archive ouverte pluridisciplinaire HAL, est destinée au dépôt et à la diffusion de documents scientifiques de niveau recherche, publiés ou non, émanant des établissements d'enseignement et de recherche français ou étrangers, des laboratoires publics ou privés. 


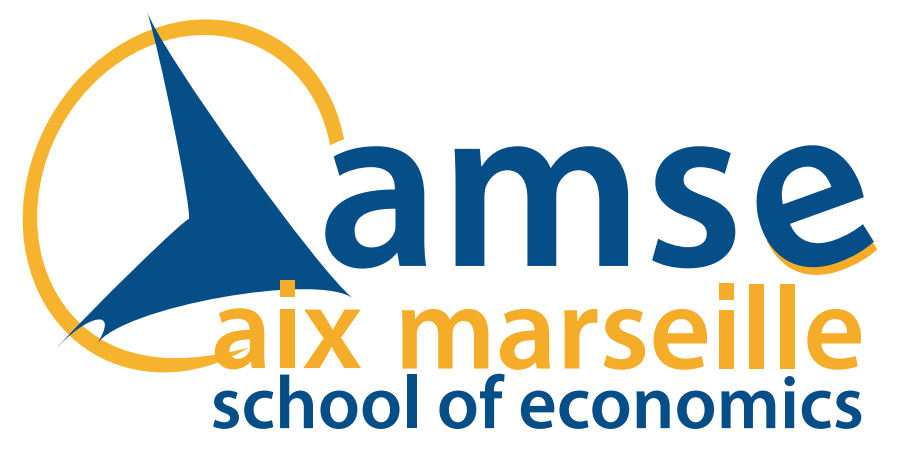

\section{Working Papers / Documents de travail}

Public Debt and Economic Geography

Federico Trionfetti 


\title{
Public Debt and Economic Geography.
}

\section{Federico Trionfetti ${ }^{*}$}

\begin{abstract}
This paper studies the consequences of debt policies on the spatial distribution of output in a two-country model. It departs from the usual set up of local public finance by relaxing the assumption of balanced budget. Further, to single out the pure effect of debt the paper eliminates effects coming from tax and expenditure policies by assuming them exogenous and identical between countries except for the timing of taxation. Expected taxation rather than current tax levels motivates migration. Starting from an initial spatial configuration, be it Core-Periphery or symmetric equilibrium, the analysis identifies the critical thresholds of divergence or convergence of debt ratios which break the initial configuration. The paper also shows that a high debt country or a fast debt reducing country is a weaker player in the tax competition game. Lastly, tax harmonisation does not necessarily reduce migration flows.
\end{abstract}

J.E.L. classification: F15, F42, F22

Key words: New Economic Geography, Economic Integration, Taxation.

\footnotetext{
${ }^{*}$ Aix-Marseille University (Aix-Marseille School of Economics), CNRS \& EHESS. Email: Federico.Trionfetti@univ-amu.fr
} 


\section{Introduction.}

The scope of this paper is to study the consequences of debt policies on the spatial distribution of economic activity and to outline some implications concerning tax competition. Like most of the literature on local public finance, this paper allows for migration of factors but, unlike most of that literature, I relax the assumption of government balanced budget at all times. Migration is driven by the intertemporal profile of taxation resulting from debt policy rather than by the current tax rates differential. Migration of factors has temporary or permanent consequences on the spatial distribution of economic activity depending on the level of economic integration and on governing debt policy. To understand the key mechanism driving migration, consider the following simplified thought experiment. Assume two identical countries that have exactly the same current tax rates and whose government budget initially balances. Now assume that one government creates public debt temporarily by reducing taxation "today" and increasing it in the "future" consistently with its intertemporal budget constraint. The discounted value of taxation "today" is unchanged. This seemingly neutral policy induces migration away from the temporarily indebted country. The reason is that by migrating between today and the future the migrant enjoys the tax reduction today and avoids the tax increase in the future. This motive for migration is absent from the literature on local public finance and is the objective of investigation in the present paper.

Two types of debt policies are analysed: temporary debt divergence (as in the example above) and debt convergence. Four major results emerge from this analysis. First, temporary debt divergence may destabilise the initial spatial configuration. Secondly, and perhaps more surprisingly, a policy of debt convergence is also likely to destabilise the initial spatial configuration. Thirdly, the ability of a country to engage in international tax competition is weakened by the debt overhang. Fourthly, a 
policy of debt convergence makes the debt reducing country a stronger player in the tax the competition game in the long run but makes it a weaker player in the short run.

The remainder of the paper is structured as follows. In section 2 I review the related literature; in section 3 I present the model; in section I 4 present a simple case; in section 5 and 6 I study, respectively, the effects of temporary debt divergence and debt convergence starting from an initial symmetric equilibrium; in section 7 I study the effects of debt converge and debt divergence starting from an agglomerated equilibrium; and section 8 I discusses the consequences of debt policies on tax competition. In the Appendix I discuss the case of perfect foresight.

\section{Relationship to the literature}

The study of the effect of debt policies on the location of economic activity is practically absent from the literature on local public finance. The closest relationship I have found is with the works on economic geography and public policies. Works in this area revisit some aspects of public policy in the light of new economic geography models though public debt is absent: Ludema and Wooton (2000) show that economic integration may result in a decline rather than in an increase of tax competition; Kind et al. (2000) highlight the complexity of the implications of economic integration on tax competition: Baldwin and Krugman (2004) find that economic integration results in an initial increase in the tax gap and subsequently in a decline as trade costs are reduced further: Brülhart, M., M. Jametti, and K. Schmidheiny (2012) find evidence that, consistently with theory, agglomeration economies attenuate the impact of tax differentials on firms location choices; Anderson and Forslid (2003) consider a model where amenities enter the utility function and have shown that, other things equal, a 
symmetric increase in taxation destabilises the symmetric equilibrium. An insightful discussion of this literature and other related works is in Baldwin et al. (2003).

Like these papers, I use a model of economic geography. Specifically, I use a simple extension of Krugman’s (1991a) “Core-Periphery” model. This choice is justified by the fact that the "Core-Periphery" model is built on a simple structure but has all the features required for the purpose of my study, namely: migration of factors, agglomeration and dispersion forces, multiple equilibria. These three elements are all essential for the story I want to tell. There are some variants to the structure of the Core-Periphery model that could be used as well. These variants concern in particular the expectation regime (Baldwin, 2001) and the assumption of factor specificity (Ottaviano, 2001; Forslid and Ottaviano, 2003). Utilising any one of these variants would not affect the results. In the Appendix I will use Baldwin's (2001) extension of Krugman (1991a) to discuss the case of perfect foresight.

I depart from the literature above and from the typical models of local public finance by relaxing the flow balanced budget constraint and replace it with the interpemporal budget constraint. Most of the local public finance literature assumes that the government budget balances at any time. This assumption is as much convenient as it is at odds with reality. In reality, governments are not in balanced budget and public debt is far from zero. I take account of this basic fact in extending the Core-Periphery model. I assume that governments' debt policies are exogenous. This seems a reasonable choice since debt policies are more often motivated by macroeconomic considerations than by economic geography. Thus, in the model governments do not use debt policies in order to influence the spatial configuration of economic activity. Nevertheless, debt policies have consequences for the spatial 
configuration of economic activity through factor migration. The consequence of these policies is what is being studied in this paper.

The link between debt and migration was first recognised by David Ricardo (1817) in his famous Principles but to date has remained vastly unexplored. I will return to Ricardo's thought in the next paragraph after having noted that, to my knowledge, only a tiny literature in local public finance has studied the link between debt and migration in modern times. Daly (1969), Oates (1972), and Wellisch and Richter (1995) take account of the link between debt and migration in their models but their focus is different from the one in the present paper. Their objective is to explore the incidence of different modes of financing local public infrastructure (Daly, 1969; Oates, 1972) and to study the debt policy that maximises the welfare of local residents (Wellisch and Richter, 1995). Furthermore, their set up is that of a small country partial equilibrium model. The present paper takes a different focus and uses a different model structure: the focus is on the consequences of debt policies on the spatial distribution of economic activity; the model structure is that of a twocountry general equilibrium model that exhibits agglomeration and dispersion forces.

I conclude this section by returning to Ricardo’s view on the link between debt and migration. The clarity of his thoughts and beauty of his prose make it irresistible to quote him verbatim. Here is what he writes (Principles, p. 247; italics added):

"A country which has accumulated a large debt, is placed in a most artificial situation; and although the amount of taxes, and the increased price of labour, may not, and I believe does not, place it under any other disadvantage with respect to foreign countries, except the unavoidable one of paying those taxes, yet it becomes the interest of every contributor to withdraw his shoulder from the burthen, and to shift this payment from himself to another; and the temptation to remove himself and his capital to another country, where he will be exempted from such burthens, becomes at last irresistible, and overcomes the natural reluctance which every man feels to quit the place of his birth, and the scene of his early associations." 
The model in this paper, among other things, gives formal shape to the intuition of the great economist.

\section{The Model.}

The structure of the model follows closely Krugman’s (1991a) Core-Periphery model but augments it with a government sector and with forward looking individuals. The world is composed of two countries $(H$ and $F)$ and is populated by infinitely lived individuals that appeared on earth at time $\mathrm{z}=0$ by fiat people. ${ }^{1}$ The world population is normalised to 1 and is composed of two types of individuals who also are the only two factors of production: skilled and unskilled labour. These two factors are available in given quantities: there are $\mu$ skilled workers and $1-\mu$ unskilled. Unskilled labour is assumed to be internationally immobile and, for the sake of symmetry, I assume that each country hosts $(1-\mu) / 2$ unskilled workers. Skilled labour may migrate. ${ }^{2}$ The state variable $\lambda_{i}(z)$ denotes country i's share of skilled labour at time z. This share may change over time if migration occurs. Obviously, $\lambda_{H}(z)=1-\lambda_{F}(z)$. I have assumed that the migration decision is taken by skilled labour. Alternatively, one may assume that the migration decision is taken by firms. It is well known, however, that in models of this class it is immaterial whether the migration decision is taken by firms or by labour; results are identical. The isomorphism among various models of this class with respect to the migration decision (and other aspects) is demonstrated in Robert-Nicoud (2005).

\footnotetext{
${ }^{1}$ The term "country" in this paper is used as a generic label for any political unit which is entitled to issue bonds and to tax its residents; it can be interpreted, for instance, as states within the United States, provinces within Canada, or countries within Europe.

${ }^{2}$ The assumption that skilled labour is internationally mobile while unskilled labour is not is made for pure convenience but it reflects some empirical evidence on migration flows; see, for instance, Shields and Shields (1989).
} 
There are two goods being produced: a homogenous good $A$ and a horizontally differentiated good $M$. Unskilled labour is the only input in the production of $A$ and skilled labour is the only input in the production of $M$. Nominal wages of unskilled and skilled workers in country $i$ are denoted with $w_{A i}$ and $w_{M i}$, respectively. As usual in this class of models, good $A$ is traded at zero cost while the differentiated good is traded internationally at an iceberg type of trade cost: for each unit shipped only a fraction $\psi \in(0,1]$ arrives at its destination. One unit of unskilled labour produces one unit of good $A$. Perfect competition in sector $A$ equalises the price of $A$ to the wage of unskilled workers. The input of skilled labour for $q$ units of output of any variety of $M$ is $f+a q$. Denoting with $\sigma$ both the perceived elasticity of demand and the elasticity of substitution among varieties and using the normalisations $f=1 / \sigma$ and $a=\sigma /(\sigma-1)$, the optimal output per firm equals 1 and the profit maximising prices for sales at home and abroad are $p_{i i}=w_{M i}$ and $p_{i j}=w_{M i} / \psi$, respectively. The number of varieties of $M$ produced in the world (which is endogenous) is constant and, using the normalisations, it is equal to 1 . The number of varieties produced in country $i$ is denoted $n_{i}$. Using the normalisations, I have that $n_{i}=\lambda_{i}$ at any time. Given the utility function specified below, both countries produce the homogeneous good as long as $\mu$ $<1 / 2$. I assume this inequality throughout the paper so that the price of $A$ is the same in both countries. Good $A$ will be used as the numéraire good and its price is set equal to 1 .

Governments are assumed to be identical in all respects except for the debt policy. Government expenditure is assumed to be a constant proportion of gross domestic product. Since this proportion does not play any role, it is convenient to save 
notation by assuming it to be zero in both countries at any time. ${ }^{3}$ It is assumed that government of country $F$ keeps the debt to a constant level (zero for simplicity). Since government expenditure is zero it follows that taxation is also zero for all individuals in country $F$. Government of country $H$, instead, operates an intertemporal reallocation of taxes which is consistent with its intertemporal budget constraitn. Total tax revenues in country $H$, denoted $T_{H}(z)$, is collected from the skilled and unskilled labour according to the following proportions: a proportion $\Phi=\varphi \lambda_{H} \mu$ of total tax revenues is collected from skilled labour and the remaining $1-\Phi$ is collected from unskilled labour. The parameter $\varphi$, which represents the tax distribution criterion, can take any value in the set $\left(0, \mu^{-1}\right)$. As a consequence, $\Phi$ will range in the set $[0,1)$. In particular, we have $\Phi=0$ only if $\lambda_{H}=0$. This means that the only constraint imposed upon the tax distribution criterion is that as long as both factors are present in the country they are both taxed. ${ }^{4}$ The resulting per capita taxation for unskilled and skilled labour in country $H \quad$ is $\quad t_{A 1}(z)=2(1-\Phi) T_{H}(z) /(1-\mu) \quad$ and $t_{M 1}(z)=\Phi T_{H}(z) / \lambda_{H} \mu$, respectively. Finally, government budgetary policies obey the following flow constraint and transversality condition:

$$
\begin{aligned}
& \dot{B}(z)-r(z) B(z)+T_{H}(z)=0 \\
& \operatorname{Lim}_{s \rightarrow \infty} B(z) \exp \left[\int_{z}^{s} r(\zeta) d \zeta\right]=0 .
\end{aligned}
$$

where $B(z)$ is government debt at time $z$ and the "dot" denotes the time derivative. Given the subjective rate of time preference $\rho$ and defining $c(z)=M^{\mu} A^{1-\mu}$,

\footnotetext{
${ }^{3}$ The consequences of government expenditure on the spatial configuration of economic activity in a similar model have been studied theoretically and empirically in Trionfetti (2001) and in Brülhart and Trionfetti (2004).
} 
individuals maximize $\int_{s=z}^{\infty} c(s) e^{-\rho(s-z)} d s$, subject to the transversality condition and to the flow constraint $\dot{k}_{s i}=r(\mathrm{z}) k_{s i}(\mathrm{z})+d_{s i}(\mathrm{z})-\varepsilon_{s i}(\mathrm{z})$, where $k_{s i}(\mathrm{z})$ denotes the stock of financial assets accumulated by an individual in $i, \varepsilon_{s i}(z)$ denotes the individual expenditure, and $d_{s i}(\mathrm{z})=w_{s i}(\mathrm{z})-t_{s i}(\mathrm{z})$ is individual disposable income. Since there may be migration, to recover aggregate values from (optimised) individual variables I index immigrants by their vintage $\xi$ of arrival in their new country of residence. Thus, aggregate variables in $i$ (denoted by upper case letters) can be computed by use of the general aggregation function (3):

$$
X_{i}(z)=\frac{1-\mu}{2} X_{i}(z)+X_{i}(0) \lambda_{i}(0) \mu-\int_{0}^{z} g_{j}(\xi, z) m_{i j}(\xi) d \xi
$$

where $m_{i j}(z)$ is the flow of migrants from $i$ to $j$ at time $z$, and $g_{j}(\xi, z)$ is the value of the variable associated with the individual that migrated to $j$ at time $\xi$ as of time $\mathrm{z}$. World aggregates are denoted by upper case letters without any subscripts and can be easily computed using the aggregation function (3). Thus, $D(z), K(z), E(z)$, and $Y(z)$ denote respectively aggregate disposable income, aggregate stock of financial assets, aggregate expenditure, and aggregate output in the world economy. The aggregate expenditure dynamics and the aggregate resource constraint are given by:

$$
\begin{aligned}
& \dot{E}(z)=[r(z)-\rho][D(z)+H(z)], \\
& Y(z)=E(z)=n_{H} p_{H H}+n_{F} p_{F F}+A .
\end{aligned}
$$

This model excludes physical capital accumulation. Therefore, expenditure jumps immediately to its steady state value. Further, since aggregate world income $Y$ is

\footnotetext{
${ }^{4}$ This assumption is slightly less restrictive than those used in the related literature. For instance Baldwin and Krugman (2004) assume $\Phi=1 / 2$ while Ludema and Wooton (2000) and Kind et al. (2000) assume that only the mobile factor is taxed $(\Phi=1)$.
} 
constant, aggregate world expenditure must be constant too, which implies that the interest rate is constantly equal to the subjective discount rate, i.e., $r=\rho$.

The market equilibrium equations for the varieties of $\mathrm{M}$ are:

$$
\begin{aligned}
& \frac{w_{M H}^{1-\sigma} Y_{H}}{\lambda_{H} w_{M H}^{1-\sigma}+\psi^{\sigma-1}\left(1-\lambda_{H}\right) w_{M F}^{1-\sigma}}+\frac{\psi^{\sigma-1} w_{M H}^{1-\sigma} Y_{F}}{\lambda_{H} w_{M H}^{1-\sigma} \psi^{\sigma-1}+\left(1-\lambda_{H}\right) w_{M F}^{1-\sigma}}=w_{M H}, \\
& \frac{\psi^{\sigma-1} w_{M F}^{1-\sigma} Y_{H}}{\lambda w_{M H}^{1-\sigma}+\psi^{\sigma-1}\left(1-\lambda_{H}\right) w_{M F}^{1-\sigma}}+\frac{w_{M F}^{1-\sigma} Y_{F}}{\lambda_{H} w_{M H}^{1-\sigma} \psi^{\sigma-1}+\left(1-\lambda_{H}\right) w_{M F}^{1-\sigma}}=w_{M F} .
\end{aligned}
$$

By Walras' law, the market equilibrium conditions for A are redundant. Equations (6) and (7) determine implicitly the wage rate in each country as a function of the distribution of skilled labour between countries; these functions are $w_{M H}\left(\lambda_{H}(z)\right)$ and $w_{M F}\left(\lambda_{H}(z)\right)$. Skilled labour migrates according to the present value of the indirect utility differential between countries. If a skilled worker stays in country $i$ for the rest of her (infinite) life, the discounted value at time $\mathrm{z}$ of her indirect utility - denoted $v_{M i}(\mathrm{z})$ - is:

$$
v_{M i}(z) \equiv \int_{z}^{\infty}\left(\frac{w_{M i}(s)-t_{M i}(s)}{\left[P_{i}(s)\right]^{\mu}}\right) e^{-\rho(s-z)} d s,
$$

where $P_{i}$ is the CES price index of $\mathrm{M}$ implied by the utility function. Skilled workers, however, may migrate. The benefit of migrating to country $j$ is the present value of the indirect utility differential between countries, which is:

$$
v_{i j}(z) \equiv v_{M j}(z)-v_{M i}(z)
$$


I follow Baldwin (2001) in assuming that moving costs take the form $\frac{\gamma \dot{\lambda}_{H}}{\lambda_{H} \lambda_{F}}$, where $\gamma$ is a positive constant. ${ }^{5}$ Equating the value of migration to moving costs at any time gives the differential equation that governs the dynamics of the model:

$$
\dot{\lambda}_{H}(z)=-\frac{\lambda_{1}(z) \lambda_{2}(z)}{\gamma} v_{H F}(z)
$$

Most of the new economic geography literature has used the assumption of static expectations. ${ }^{6}$ In the main text of this paper I assume that individuals formulate rational expectations under imperfect information about future values of prices and wages. This will enable an easier comparison between the results in this paper and those in the related literature. Further, it will allow us to concentrate on the key economic mechanism at work.

It is important to bear in mind, however, that assuming perfect foresight (i.e., rational expectations and perfect information) does not change the essence of the results. This is formally demonstrated in the Appendix.

Assuming for the time being rational expectations and imperfect information, the expectation regime is as follows: individuals do not have information as to the future values of wages and prices. That is, they ignore the implicit functions $w_{M H}\left(\lambda_{H}(z)\right)$ and $w_{M F}\left(\lambda_{H}(z)\right)$, as well as $P_{H}(z)$ and $P_{F}(z)$. Therefore, they use current wages as best predictors of future wages and they update their prediction every instant as current wages evolve over time. Yet, they are aware of the government's intertemporal budget constraint and they use this information to

\footnotetext{
${ }^{5}$ Any form of moving costs that gives rise to a differential equation $\dot{\lambda}_{H}(z)=-f\left(v_{H F}(z)\right)$, where $f$ is a sign preserving function and $f(0)=0$, can be used without affecting the results. The specification in the text is analytically convenient and can be thought intuitively as a queuing system with random selection. For its microfoundations see Baldwin (2001).

${ }^{6}$ The only exceptions, besides Krugman (1991b), are Baldwin (2001) and Ottaviano (2001).
} 
formulate expectations on future tax liabilities. With these assumptions the expected value of $v_{M i}(z)$ is:

$$
\mathrm{E}\left[v_{i}(z)\right]=\int_{z}^{\infty}\left(\frac{w_{M i}(z)-t_{M i}(s)}{\left[P_{i}(z)\right]^{\mu}}\right) e^{-\rho(s-z)} d s,
$$

where $\mathrm{E}$ is the expectations operator. The assumption about imperfect information on future wages, while not unrealistic, is unsatisfactory from the conceptual point of view. This is why in the Appendix I remove this restrictive assumption and show that the essence of the result shown in the main text of the paper does not change when I assume perfect foresight (i.e., rational expectations and perfect information). In particular, all the propositions in this paper remain valid. For expositional purposes, however, it seemed more insightful to keep the main text of this paper as close as possible to the related literature. This expositional choice should make it easier to understand the key economic mechanism in the model.

Lastly, I assume that the migration process is anonymous; at any point in time

there are $\dot{\lambda}_{H}(z)$ "tickets" available to country $F$ and migrants are chosen randomly. Since individuals are identical, the anonymity of the migration process is irrelevant for the results.

\section{Temporary debt divergence and migration: understanding the key mechanism.}

It is convenient to begin the analysis of the debt policy by assuming zero trade costs. In the absence of trade costs there are neither agglomeration nor dispersion forces. The absence of these forces will allow us to focus on the relation between debt and migration. Trade costs will be resumed in the next section. 
Consider two countries which differ only in the tax profile of taxation. Precisely, government debt is initially zero in both countries; government $F$ keeps its budget balanced at any time while government $H$ creates public debt temporarily by undertaking an intertemporal reallocation of taxes. More precisely, government $H$ unexpectedly reduces tax collection by an amount equal to $\alpha$ at time $z_{0}$ and increases it by an amount equal to $\beta$ at time $z_{1}{ }^{7}$ So, that the only difference between countries is in the time profile of taxation. Note that $z_{0}$ and $z_{1}$ are points in time, they are instants. Therefore, per capita taxation is identical between countries at all times except in the two instants $z_{0}$ and at $z_{1}$. Mathematically, this tax profile is obtained by specifying $T_{H}(z)$ as a linear combination of two Dirac functions which impart a tax impulse equal to $\alpha$ at time $z_{0}$ and equal to $\beta$ at time $z_{1}$. The use of Dirac functions allows us to keep per capita taxation the same in both countries at all times except at $\mathrm{z}_{0}$ and $\mathrm{z}_{1}$. In this way migration is triggered solely be the intertemporal tax reallocation and not by current differences in tax rates. Using equations (1) and (2) I obtain the value of $\beta$ consistent with the intertemporal budget constraint of the government, this is: $\beta=-\alpha e^{r\left(z_{1}-z_{0}\right)} \cdot{ }^{8}$ Individuals foresee the tax increase represented by $\beta$ awaiting them at $z_{1}$. Skilled labour can avoid the tax increase by migrating to country $F$ before $z_{1}$. Using (11) and (9) the expression for the benefit of moving to country $F$ is given by: ${ }^{9}$

$$
v_{H F}(z)= \begin{cases}-\varphi \alpha e^{r\left(z_{1}-z_{0}\right)} e^{-r\left(z_{1}-z\right)}>0 & \forall z \in\left[z_{0}, z_{1}\right) \\ 0 & \forall z<z_{0}, \text { and } \forall z \geq z_{1}\end{cases}
$$

\footnotetext{
${ }^{7}$ Residents of country $H$, unlike residents of country $F$, have their consumption path disrupted by the unexpected tax reduction. They will therefore buy government $H$ 's bonds as they need them for consumption smoothing.

${ }^{8}$ The use of Dirac functions turns out to be useful analytically in that the Fourier transform of a Dirac, which we encounter in the integration of (1) subject to (2), is an exponential function.

${ }^{9}$ Note that, after substituting $T_{H}(z)$ into $t_{M H}(z)$, expression (11) is a linear combination of Fourier transforms of the Dirac functions constituting $T_{H}(z)$.
} 
Expression (12) shows that between $\underline{z}_{0}$ and $\underline{z}_{1}$ a skilled worker in country $H$ benefit from moving to country $F$. He has the opportunity to avoid paying the taxes that will be levied at $z_{1}$ to reduce the debt. In Ricardo’s words, he will be able “to withdraw his shoulder from the burthen, and to shift this payment from himself to another". Precisely, by migrating he will save $-\varphi \alpha e^{r\left(z_{1}-z_{0}\right)} e^{-r\left(z_{1}-z\right)}>0$ and this burden will fall on those who remain in country $H$. The term $-\varphi \alpha e^{r\left(z_{1}-z_{0}\right)}$ is the increase in taxation waiting for any skilled worker at $z_{1}$. Multiplying it by the discount factor $e^{-r\left(z_{1}-z\right)}$ gives us the impact on the indirect utility differential at any z. Apart from the tax distribution parameter $\varphi$, the present value of future tax liabilities equals the current size of public debt; indeed $\alpha e^{r\left(\mathrm{z}_{1}-z_{0}\right)} e^{-r\left(\mathrm{z}_{1}-z\right)}=\alpha e^{r\left(z-z_{0}\right)}=B(z)$.

Migration is governed by differential equation (10) where $v_{H F}(\mathrm{z})$ is given by (12). The amount of skilled labour that will have migrated to country $F$ at $z_{1}$ depends on the migration cost $(\gamma)$; on the size of the initial tax reduction $(\alpha)$; on the tax distribution parameter $(\varphi)$; and on the time length between the tax cut and the tax increase $\left(\mathrm{z}_{1}-\mathrm{z}_{0}\right)$.

It is interesting to contrast the temporary nature of the debt policy with the permanent effect on migration. The intertemporal reallocation of taxes creates only a temporary divergence of the debt ratio between countries; indeed, after $z_{1}$ debt is zero in both countries. Yet, this temporary divergence of debt ratios has permanent consequences on the international distribution of the mobile factor. The reason is that after $z_{1}$, there is no point in migrating in either direction since $v_{H F}(z)=0$ forever. So, the skilled labour that has migrated will stay put, and the spatial configuration of economic activity will have permanently changed.

It is important to recall once more that migration is triggered solely by the intertemporal tax reallocation and not by differences in tax levels; tax levels are 
identical between countries at any time except at $z_{0}$ and at $z_{1}$. This is interesting because it shows that simply removing the assumption of balanced budget reveals a new motive for migration which is absent in balanced budget models.

There is an implication of this analysis for the tax harmonisation debate that is worth pointing out: the harmonisation of current tax rates without the convergence of debt ratios (future tax liabilities) does not necessarily reduce migration of the tax base.

\section{Temporary Debt Divergence, Temporary Spatial Fluctuations and} Agglomeration.

I now reintroduce trade costs to the model. Introducing trade costs generates agglomeration and dispersion forces that make the real and nominal wage of skilled workers depend on their geographical distribution. Therefore, migration does not stop when the debt ratios are again zero in both countries (i.e., at $z_{1}$ ). The direction of migration after $z_{1}$ depends on whether agglomeration or dispersion forces dominate the dynamics of the model at $z_{1}$. This, in turn, depends on the geographical distribution of skilled labour at $z_{1}$. To illustrate the mechanism, consider again an initial situation where government debt is zero in both countries. Government $F$ keeps its budget balanced at any time. Government $H$ follows the same debt policy as in the previous section: it generates public debt temporarily, between $\mathrm{z}_{0}$ and $\mathrm{z}_{1}$. Denoting the real wages of skilled workers $\omega_{F} \equiv w_{M F} / P_{F}{ }^{\mu}, \omega_{H} \equiv w_{M H} / P_{H}{ }^{\mu}$, defining the real wage differential between country $F$ and country $H$ as $\omega \equiv \omega_{F}-\omega_{H}$, using (1), (2), (9) and (11) I have the following piecewise expression for the benefit of migrating to country F: 
$v_{H F}(\mathrm{z})=\left\{\begin{array}{ll}\frac{1}{r} \omega-\varphi \alpha e^{r\left(z-z_{0}\right)} & \forall z \in\left[z_{0}, z_{1}\right) \\ \frac{1}{r} \omega & \forall z<z_{0}, \text { and } \forall z \geq z_{1}\end{array}\right.$,

The first term in the upper line of (13) is the real wage differential and the second term is the expected tax increase at $z_{1}$ discounted to time $z$. Skilled labour in country $H$ can avoid the burden of debt repayment by migrating to country $F$ before $\mathrm{z}_{1}$. Migration is governed by differential equation (10) where $v_{H F}(z)$ is given by (13). At $\mathrm{z}_{0}$ the term $(1 / r) \omega$ is equal to zero. Migration is triggered at $\mathrm{z}_{0}$ by the term $-\varphi \alpha e^{r\left(z-z_{0}\right)}$ which, instead, is positive. From $\mathrm{z}_{1}$ onward expected tax liabilities are zero in both countries but migration continues until real wages are equalised or until the mobile factor is all in one country. The long run spatial configuration is determined by the size of trade costs, the size of migration costs and the size and timing of debt policy. I shall assume a level of trade costs such that gives rise to multiple stable spatial configurations. This is the most interesting case for the analysis I want to perform. The case of a unique stable and unique unstable spatial configuration can be easily understood once the case of multiple stable spatial configurations has been studied. ${ }^{10}$ Figure 1 shows the phase diagram of the differential equation (10) when trade costs give rise to multiple stable spatial configurations. The solid line represents the phase line before $z_{0}$ and after $z_{1} \cdot{ }^{11}$ So, before $z_{0}$ and after $z_{1}$ there are three internal equilibria, each at the intersection of the phase line with the horizontal axis. Henceforth, I will refer to the equilibrium in the

\footnotetext{
${ }^{10}$ In focusing on the most interesting case I follow a widely used expositional strategy. For instance, Baldwin and Krugman (2004) concentrate on the Core-Periphery outcome, Ludema and Wooton (2000) modify the model in order to eliminate the possibility of multiple stable configurations, and Anderson and Forslid (2003) focus on the stability of the symmetric spatial configuration.

${ }^{11}$ The system (8) and (9) cannot be solved explicitly for $\omega\left(\lambda_{H}\right)$. Therefore, I approximate $\omega\left(\lambda_{H}\right)$ with a continuous polynomial. I use Chebyshev's approximation method instead of Lagrange as the former performs remarkably better (see Judd, 1998). The approximation has been computed for the following parameter values: $\mu=0.4, \sigma=3, \psi=0.15$.
} 
middle as the Central spatial configuration $\left(\lambda_{C}\right)$ and I will refer to the two lateral equilibria as the Left and the Right spatial configuration $\left(\lambda_{L}\right.$, and $\left.\lambda_{R}\right)$.

Figure 1

The spatial effects of temporary debt divergence: phase lines.

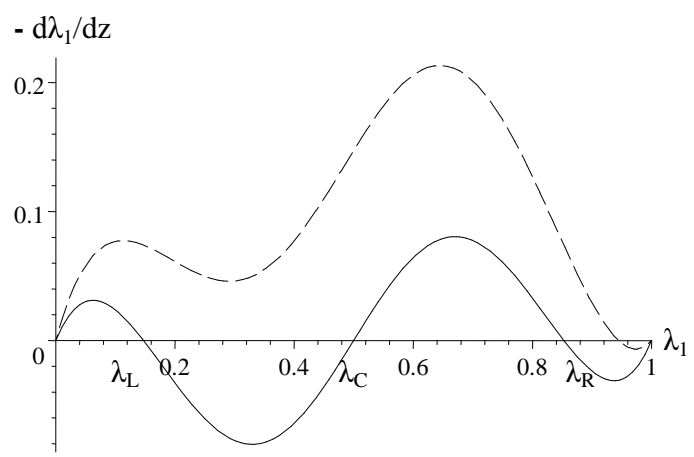

Inspection of the phase line gives the stability properties of the equilibria. Note that the phase line in Figure 1 has sign reversed with respect to the phase line appearing, for instance, in Krugman (1991) or in Baldwin (2001) or Baldwin et al. (2003). This is so because I have found more intuitive to define $v_{H F}(z)$ as the benefit of migrating to country $F$ and I have accordingly defined $\omega$ as $\omega \equiv \omega_{F}-\omega_{H}$. Taking account of this sign reversion, in the present paper a positively sloped intersection of the phase line with the horizontal axis implies a stable equilibrium and a negatively-sloped intersection indicates an unstable equilibrium. Figure 1 shows that the Central configuration is stable while the lateral configurations are unstable. There are two more stable spatial configurations known as the "Core-Periphery" configurations, these are: $\lambda_{H}=0$ and $\lambda_{H}=1$. In the former $\left(\lambda_{H}=0\right)$ country $F$ is the Core, in the latter $\left(\lambda_{H}=1\right)$ country $H$ is the Core. Assume the economy is in $\lambda_{\mathrm{C}}$ at $\mathrm{z}_{0}$. The intertemporal reallocation of the tax burden shifts the phase line upward between $z_{0}$ and $z_{1}$. Consequently, the equilibria $\lambda_{L}$, and $\lambda_{C}$ approach each other and might eventually disappear if the phase line shifts up enough (like the dashed line in Figure 1). At $z_{1}$, the phase line drops to its initial position. From $\mathrm{z}_{1}$ onward, the set $\left(\lambda_{L}, \lambda_{R}\right)$ is the basin 
of attraction of $\lambda_{C}$ and the set $\left(0, \lambda_{L}\right)$ is the basin of attraction of the Core-Periphery configuration $\lambda_{H}=0$. Which of the two spatial configurations will emerge in the long run depends on whether at $\mathrm{z}_{1}$ the state variable is in the basin of attraction of $\lambda_{H}=0$ or of $\lambda_{C}$. If $\lambda_{1}\left(z_{1}\right) \in\left(0, \lambda_{L}\right)$, then the system will asymptotically approach the CorePeriphery configuration $\lambda_{H}=0$. Conversely, if $\lambda_{H}\left(z_{1}\right) \in\left(\lambda_{L}, \lambda_{C}\right)$, the system will asymptotically return to the central configuration. The value of $\lambda_{H}\left(z_{1}\right)$ is smaller the smaller are migration costs, the larger is the size of the tax cut, and the longer is the time period of debt divergence $\left(z_{1}-z_{0}\right)$.

Using computer simulations it is possible to find the time path of $\lambda_{H}(z)$ for different values of $\alpha$ and $\gamma$. Figure 2 illustrates two representative cases. On the ordinates I have $\lambda_{H}$ and on the abscissa I have time (z). In both simulations $z_{1}=32$ and $z_{0}=0$. The intertemporal rate of time preferences was set at $5 \%$. The dashed line represents the case of high migration costs while the dot-dashed line represents the case of low migration costs. In the simulations, the values assigned to $\gamma$ were 1.5 and 1.2 respectively, thus simulating a $20 \%$ drop in migration costs. The value assigned to $\alpha$ was $-10 \%$ of the initial GDP. The distributional parameter $\varphi$ was set at $\varphi=0.8$. The solid horizontal line intercepts the vertical axis in correspondence of $\lambda_{L}$ (the same value as in Figure 1). With the parameter values chosen for this simulation the two lines representing the time paths are visually distinguishable only after $z=20$, which is where the abscissa starts in the Figure 2. For low migration costs I have $\lambda_{1}\left(z_{1}=32\right) \in\left(0, \lambda_{L}\right)$ (dot-dashed line), therefore, after $z_{1}$ the system continues on an unstable path asymptotically approaching the Core-Periphery configuration. For high migration costs I have $\lambda_{1}\left(z_{1}=32\right) \in\left(\lambda_{L}, \lambda_{R}\right)$, therefore, after $z_{1}$ the system asymptotically returns to its initial equilibrium $\left(\lambda_{C}\right)$. The latter is a case of temporary 
reconfiguration of economic activity in space. It is as an economic fluctuation in the geographical space and I refer to it as to "temporary spatial fluctuation”. Similar patterns to those illustrated in Figure 2 would emerge if, keeping migration costs constant, I considered large and small $\alpha$.

Figure 2

The spatial effects of temporary debt divergence: time path.

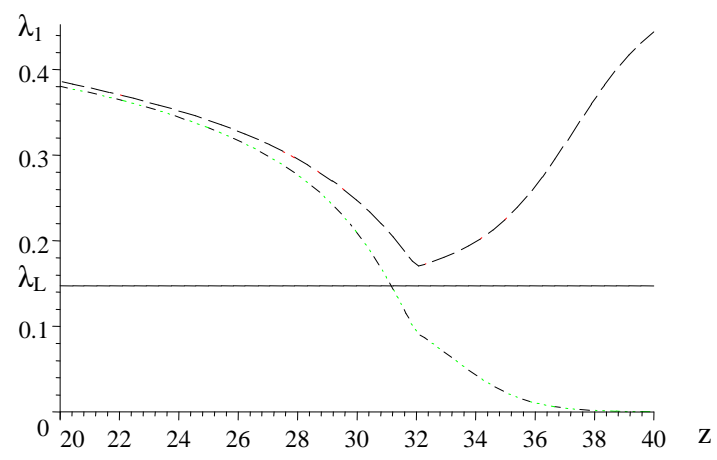

The result of this analysis is that a temporary divergence of debt ratios generates either a temporary spatial fluctuation or the Core-Periphery outcome. The amplitude of the fluctuation and the likelihood of the core periphery configuration decrease with $\gamma$ and increase with $|\alpha|$ and $z_{1}-z_{0}$. Let $b_{b, \text { div }}$ denote the maximum divergence of debt ratios such that $\lambda_{H}\left(z_{1}\right)$ is in the basin of attraction of $\lambda_{C}$. I refer to $b_{b, d i v}$ as to the "break-point debt divergence". A temporary divergence of debt ratios beyond the "break-point debt divergence" results in the Core-Periphery configuration. The relative size of migration cost, trade costs, tax reduction at $z_{0}$ and length of the existence of the debt, and the interest rate ultimately determine the long run outcome. We can summarise the results of this section as follows: 
Proposition 1. A temporary divergence of debt ratios causes either a temporary spatial fluctuation or permanent agglomeration depending on whether the divergence of debt ratios has reached a level below or above the "break-point debt divergence", respectively.

This result suggests that a large, albeit temporary, divergence of debt ratios may have permanent consequences on the spatial distribution of the mobile factor. Even small temporary divergences of debt ratios are not free from insidious complications, however. Indeed, if trade costs or migration costs fall during the adjustment process, what could initially have been a temporary spatial fluctuation might result in permanent agglomeration.

In the next section I turn to the question of whether the convergence of debt ratios may help stabilising the initial spatial configuration. Interestingly, the answer is not necessarily positive.

\section{Debt Convergence, Temporary spatial fluctuations and Agglomeration.}

Consider an initial situation of stable but different debt ratios in the two countries. Without loss of generality it is assumed that the debt ratio is equal to zero in country $F$ and is positive in country $H$. The intertemporal budget constraint of government $H$ requires that taxation be higher in county $H$ due to the need to service the debt. This difference in per capita taxation has induced migration in the past, which has shifted the central spatial configuration to $\lambda_{C}^{\prime}$ on the left of $1 / 2$. It is assumed that the economies have already reached the stable spatial configuration $\lambda_{C}^{\prime}$ when the policy of debt convergence is announced. Formally, this means assuming that $B_{H}(z) / Y_{H}(z)=\overline{\bar{b}}>0$, where $\overline{\bar{b}}$ is a constant and $Y_{H}=((1-\mu) / 2) w_{A H}+\lambda_{H} \mu w_{M H}$ is 
country H's GDP. This implies that $\dot{\lambda}_{H}(z)=0$ for $z \in\left(z_{0}-\delta, z_{0}\right)$, where $\delta>0$ and $z_{0}-\delta$ is the time at which $\lambda_{H}$ had reached the steady state $\lambda_{C}^{\prime} \cdot{ }^{12}$ Using numerical simulations and assigning the values $\overline{\bar{b}}=0.9$ and $\varphi=0.8$ I obtain $\lambda_{H}\left(z_{0}\right)=\lambda_{C}^{\prime} \approx 0.363$. At $z_{0}$ government $H$ announces that it will reduce the debt ratio from the current level $\overline{\bar{b}}$ (90\% of GDP) to a lower level $\bar{b}<\overline{\bar{b}}$ by time $z_{1}$. In the simulation I set $\bar{b}=0.6$ (60\% of GDP). To achieve this reduction of the debt ratio, government $H$ must increase taxation sometime between $z_{0}$ and $z_{1}$. The expected future tax liability triggers the migration of skilled labour. Using (1), (2), (9) and (11) I obtain the following piecewise function:

$v_{H F}(z)= \begin{cases}\frac{1}{r} \omega+\varphi B(z) & \forall z \in\left(z_{0}-\delta, z_{0}\right) \\ \frac{1}{r} \omega+\varphi B(z)+\varphi\left[B\left(z_{1}\right)-\bar{b} Y\left(z_{1}\right)\right] e^{-r\left(z_{1}-z\right)} & \forall z \in\left(z_{0}-\delta, z_{0}\right), \\ \frac{1}{r} \omega+\varphi B(z) & \forall z \geq z_{1}\end{cases}$

These expressions can be inspected in conjunction with Figure 3.

Figure 3

The spatial effects of debt convergence: phase lines.

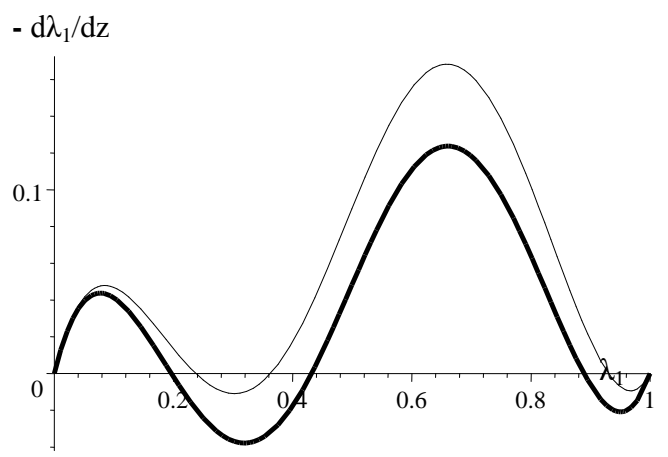

\footnotetext{
${ }^{12}$ To be precise, since the adjustment is asymptotic, $z_{0}-\delta$ is the time at which $\lambda_{H}$ was arbitrarily close to $\lambda_{C}^{\prime}$.
} 
The thin line in Figure 3 is the phase line of differential equation (10) at any $z$ before the debt reduction is announced; in such case the relevant expression for $v_{H F}(z)$ is given in the upper line of (14). Since adjustment has taken place in the past the dynamic system is at rest on the central spatial configuration is at $\lambda_{C}^{\prime} \approx 0.363$ where the benefit of migrating to country $F$ is zero. At $\mathrm{z}_{0}$ the phase line shifts upward (not shown in the figure) because of the jump in the future tax liability represented by the third term in the second line of (14). An individual moving to country $F$ before $\mathrm{z}_{1}$ will avoid such tax increase. At $\mathrm{z}_{1}$ the phase line drops down and is represented by the thick line, which is obtained by substituting the bottom expressions of (14) into differential equation (10). At $z_{1}$ the discounted values of expected future tax liability are again zero in both countries but the system is in motion because the value of $\lambda_{H}\left(z_{1}\right)$ is such that real wages are different between countries. The long run spatial configuration depends on whether $\lambda_{H}\left(z_{1}\right)$ is in the basin of attraction of the CorePeriphery or of the central configuration. In the former case the system will asymptotically approach the Core-Periphery configuration; in the latter case the system will asymptotically approach the central spatial configuration $\lambda_{C}^{\prime}$ on the thick line. The value of $\lambda_{H}\left(z_{1}\right)$ is smaller, the smaller are migration costs and the larger is the difference $(\overline{\bar{b}}-\bar{b})$. Using numerical methods it is possible to find the path of $\lambda_{H}(\mathrm{z})$ for different values of $\bar{b}$ and $\gamma$.

Figure 4 illustrates the cases of high and low migration costs; in the simulations the values assigned to $\gamma$ were 1 and 0.9 , thus simulating a $10 \%$ drop in migration costs. In both cases $z_{1}-z_{0}=6$. The dashed line represents the time path of the state variable in the case of high migration costs (the temporary spatial fluctuation) while the dash-dotted line represents the case of small migration costs 
(the agglomeration case). A similar pattern is obtained by computing high and low $\bar{b}$ respectively.

Figure 4

The spatial effects of debt convergence: time path.

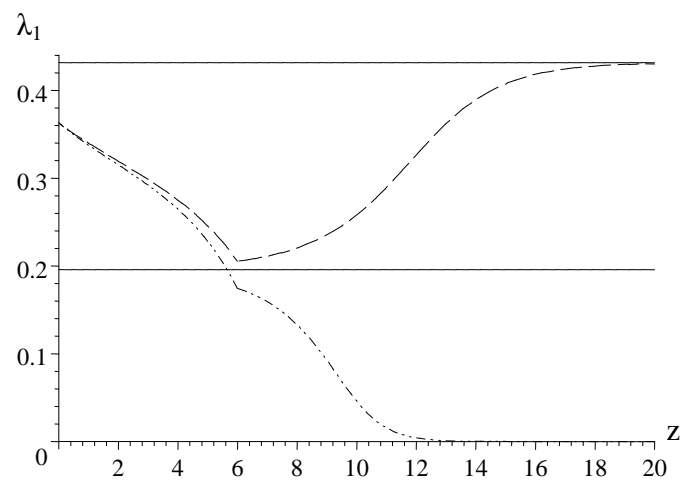

Figure 4 represents a general pattern found with simulations: the amplitude of the fluctuation increases with the tightness of budgetary convergence (low $\bar{b}$ ) and with the inverse of migration costs (low $\gamma$ ). Let $b_{b, \text { conv }}$ denote the maximum reduction of the debt ratio that leaves $\lambda_{H}\left(z_{1}\right)$ in the basin of attraction of $\lambda_{C}$ (on the thick line) and let refer to it as the "break-point debt convergence". That is $b_{b, \text { conv }} \equiv \operatorname{Max}(\overline{\bar{b}}-\bar{b})$ such that $\lambda_{H 1}\left(z_{1}\right) \in\left(\lambda_{L}, \lambda_{R}\right)$. We can summarise the results of this section as follows.

Proposition 2. Debt convergence generates a temporary spatial fluctuation or permanent agglomeration depending on whether the magnitude of debt convergence $(\overline{\bar{b}}-\bar{b})$ reaches a value below or above the "break-point debt convergence”.

These results suggest that convergence of debt ratios should be pursued with caution because it induces migration of the mobile factor and, with it, migration of the tax base. A too ambitious budgetary target (low $\bar{b}$ ) induces larger fluctuations and increases the likelihood of agglomeration. Further, unexpected declines in transport or 
migration costs may deteriorate the situation by transforming a fluctuation into permanent agglomeration.

The results also suggest that economic integration renders the achievement of debt convergence increasingly difficult. This is because the fall of trade or migration costs causes an increase in the amplitude of the fluctuation and in the likelihood of agglomeration.

\section{Debt convergence, debt divergence, and the stability of the Core-Periphery configuration.}

The impact of the debt policy on the stability of the Core-Periphery configuration can be easily studied by appeal to intuition since the economic mechanisms that come into play are the same as those in the previous section. Consider an initial situation where both countries have no debt and, initially, country $H$ is the Core. The real wage differential $\omega(1)$ is negative since real wages are higher in the core than in the periphery. That makes it possible for country $H$ to have a permanently higher level of debt and taxation without destabilising the CorePeriphery situation. Let $b_{s, c p}$ denote the maximum debt ratio differential that can be sustained permanently without destabilising the Core-Periphery configuration. Let us refer to $b_{s, c p}$ as the "sustain debt gap". Using (6), (7), (9) and the definition of gross domestic product I have: $b_{s, c p}=\frac{-2 \omega(1)}{(1+\mu)(2 \varphi \rho)}$.

Let us now consider a temporary divergence of debt ratios. The debt ratio differential can temporarily be larger than the "sustain debt gap" without country $H$ necessarily losing the core. If country $H$ is not to lose the core, the maximum debt divergence must be such that $\lambda_{H}$ does not leave the basin of attraction of the core. There is a 
critical time $z_{s}$ such that $\lambda_{H}$ at $z_{s}$ is on the border of the basin of attraction of the core. Any intertemporal tax reallocation longer than $z_{s}-z_{0}$ brings $\lambda_{H}$ outside the basin of attraction of the Core-Periphery configuration. The likelihood that country $H$ loses the core increases with the size of the tax cut, with the time length of the intertemporal tax reallocation, as well as with a fall in migration and trade costs.

The last question I ask concerns debt convergence. Assume, for simplicity, that country $H$ has a stable debt ratio equal to $b_{s, c p}$, so that there is no migration (any constant level lower than $b_{s, c p}$ can be assumed without affecting the results. If country $H$ commits to a reduction of the debt ratio to $\bar{b}<b_{s, c p}$ by $z_{1}$, expected taxation increases and skilled labour starts migrating to country $F$. After $z_{1}$ the Core-Periphery configuration is indeed stable because $\bar{b}<b_{s, c p}$ but $\lambda_{H}$ may have left the basin of attraction of the Core-Periphery configuration in the meantime. If that happens, country $H$ loses the core permanently.

The two results of this section can be summarised in the following proposition.

Proposition 3. Temporary debt divergence as well as permanent debt convergence may result in the break-up of the core. The break-up of the core is more likely to happen if factor markets are more integrated, if the debt divergence is large, or if debt reduction is big.

Somewhat surprisingly, the results in this and the previous section tell us that debt convergence may be as destabilising as temporary debt divergence. 


\section{Implications for tax competition.}

In this section I study the consequences of removing the balanced budget assumption on the ability of a country to engage in tax competition. In particular, I study the ability of a country to defend the core when the assumption of balanced budget is removed.

Assume that country $H$ is the Core (i.e., $\lambda_{H}=1$ ) and that country $F$ always keeps a balanced budget. Let $\tau_{R}$ denote the "residual limit tax". This is defined as the maximum residual per capita tax level that allows country $H$ to keep the core. The term "residual" means the level of tax above the level necessary to serve the debt. ${ }^{13}$ An example will clarify the matter. Consider the case in which debt is zero in both countries. Since country $H$ is the Core, the real wage of skilled labour is larger in country $H$ than in country $F$. The residual limit tax in this case is equal to the real wage differential, i.e.: $\tau_{R}=\omega_{H}(1)-\omega_{F}(1)$. Indeed, country $H$ can increase permanently its per capita tax level to $\tau_{R}$ without losing the core. The larger $\tau_{R}$ the stronger is country H's ability to defend the core in a tax competition game (see Baldwin and Krugman, 2004).

To continue with the example, assume now that both countries have permanently constant debt ratios, $\bar{b}_{H}$ and $\bar{b}_{F}$, respectively, and let $\bar{b}_{H}>\bar{b}_{F}$. Then, the residual limit tax is:

$$
\tau_{R}=\omega_{H}(1)-\omega_{F}(1)-\left(\bar{t}_{M H}-\bar{t}_{M F}\right)
$$

where the term in parentheses represents the permanent tax level differential resulting from both countries' need to service the debt. Since $\left(\bar{t}_{M H}-\bar{t}_{M F}\right)>0$, it is clear that the

\footnotetext{
${ }^{13}$ The "residual limit tax" is a concept akin to Baldwin and Krugman (2004) "limit tax". Indeed the two definitions coincide if both countries are in balanced budget.
} 
residual limit tax has become smaller with respect to the case of zero debt in both countries. Consequently, country H's ability to defend the core is reduced.

Consider, finally, a policy of debt reduction whereby country $H$ announces at time $z_{0}$ that the debt ratio will be reduced from $\bar{b}_{H}$ to $\overline{\bar{b}}_{H}$ at $z_{1}\left(\bar{b}_{H}>\overline{\bar{b}}_{H}\right)$. This gives: $\tau_{R}(z)= \begin{cases}\omega_{H}(1)-\omega_{F}(1)-\left(\bar{t}_{M H}-\bar{t}_{M F}\right)-\theta(z) & \text { for } \forall z \in\left(z_{0}, z_{1}\right) \\ \tau_{R}(z)=\omega_{H}(1)-\omega_{F}(1)-\left(\overline{\bar{t}}_{M H}-\bar{t}_{M F}\right) & \text { for } \forall z \geq z_{1}\end{cases}$

where $\theta(z)$ is the value at $z$ of the tax increase that will take place at $z_{1}$. Since $\left(\overline{\bar{t}}_{M H}<\bar{t}_{M F}\right)$, it follows that the policy of debt reduction will increase the residual limit tax after $z_{1}$ but, during the transition period, the residual limit tax declines. Therefore, a policy of debt reduction makes a country a stronger player in the tax competition in the long run but makes it a weaker player in the short run. We can summarise the results of this section in the following proposition.

Proposition 4. Temporary debt divergence temporarily weakens a country's ability to engage in tax competition. A policy of debt convergence makes the debt reducing country a stronger player in tax competition in the long run but makes it a weaker player during the period of debt reduction.

Equations (15) and (16) show clearly the insight that removing the assumption of balanced budget brings to light. The balanced budget tax competition analysis neglects the terms $\left(\bar{t}_{M H}-\bar{t}_{M F}\right)$ and $\theta(z)$. Neglecting the constant term $\left(\bar{t}_{M H}-\bar{t}_{M F}\right)$ conceals the fact that, other things equal, countries with a permanently larger debt ratio are weaker players in international tax competition because their residual limit tax is smaller. Neglecting the term $\theta(z)$ obscures the fact that, other things equal, a 
core country's ability to engage in tax competition may be reduced by the need to reduce the debt.

Proposition 4 highlights a number of interesting implications. Core countries with high debt or core countries undergoing a debt reduction should, other things equal, be averse to tax competition because their residual limit tax is (temporarily) smaller and their ability to defend the core is temporarily reduced. Conversely, small countries with low debt should be against tax harmonisation because they have a bigger chance of “snatching” the core. A country's aversion to tax competition may change over time; once debt reduction is achieved a country may become more favourable to tax competition.

\section{Conclusion}

This paper has studied the effects of debt divergence and debt reduction on the spatial distribution of output. The analysis departs from the local public finance literature by removing the assumption of flow balanced budget. The paper focuses on migration motivated by the desire to avoid future tax liabilities.

An immediate consequence of relaxing the balanced budget assumption is that tax harmonisation does not necessarily reduce migration of factors unless it is done in an environment where debt ratios are not diverging.

When agglomeration and dispersion forces are present, debt policies have some additional consequences. A policy of temporary divergence of debt ratios generates a temporary spatial fluctuation or permanent agglomeration depending on whether the divergence of debt ratios has reached a level below or above the "breakpoint debt divergence”, respectively (Proposition 1). The likelihood of permanent 
agglomeration increases with a decline in migration costs and with the magnitude of the debt divergence.

Somewhat surprisingly, a policy of debt convergence may also be destabilising. Debt convergence implies an increase in future tax liabilities in the high debt country, which induces migration of the mobile factor away from the debt reducing country. Debt reduction generates a temporary spatial fluctuation or permanent agglomeration depending on whether the magnitude of debt convergence reaches a value below or above the "break-point debt convergence”.

The two results just discussed show that policies that restrain debt divergence have indeed a stabilising effect on the spatial distribution of output. Conversely, policies of debt convergence, if too ambitious, may have destabilising effects. This result suggests a sequencing of economic integration policies when the destabilisation of the pre-integration spatial equilibrium is undesirable. Since debt convergence is more likely to be destabilising when migration costs are low, it would seem safer that debt convergence be achieved before the integration of labour and goods markets rather than after.

The paper has further shown that the Core-Periphery spatial configuration becomes unsustainable when debt divergence is sufficiently large or when the debt convergence policy is too ambitious (proposition 3).

The last section of the paper has shown that countries with high debt are weaker players in the tax competition game and that debt reduction makes the core country weaker in the short run and stronger in the long run (proposition 4). This implies that large countries with high debt should be averse to tax competition, while small countries with small debt should be averse to tax harmonisation. 


\section{Appendix: Perfect foresight.}

With perfect foresight (rational expectation and perfect information) the dynamic system becomes:

$$
\begin{aligned}
& \dot{v}=r \hat{v}-\omega-r \varphi \alpha e^{r\left(z-z_{0}\right)}\left(1-u_{z_{1}}(z)\right) \\
& \dot{\lambda}=-\frac{\lambda_{1}\left(1-\lambda_{1}\right)}{\gamma} v
\end{aligned}
$$

where $u_{z_{1}}(z)$ is a unit step function and $\hat{v}$ is the discounted value of $\omega$. It may be useful to note that, if we neglect the last term in (A.1), the system is isomorphic to the system in Ottaviano (2001) and Baldwin (2001). The main feature of this system is that for certain constellations of parameters it exhibits multiple saddle paths.

The effect of debt divergence on the dynamic system is qualitatively the same as illustrated in the text: future tax liabilities, represented by the last term in (A.2), act like a forcing function to the system shifting it smoothly between $z_{0}$ and $z_{1}$; at $z_{1}$ the system returns to the position it had before $z_{0}$. The effect of the forcing function is simply to shift temporarily all the phase trajectories. The long run equilibrium then depends on which saddle path will be reached at $z_{1}$. This depends crucially on the position reached by $\lambda_{H}$ at $z_{1}$ and on the size of migration costs. Three cases may emerge. $^{14}$

(1) Large migration cost. In this case there is no overlap of the saddle paths. The jumping variable $v$ will jump on a saddle path leading to $\lambda_{C}$ if $\lambda_{H}\left(z_{1}\right) \in\left(\lambda_{L}, \lambda_{R}\right)$. Instead, if $\lambda_{H}\left(z_{1}\right)<\lambda_{L}$ or $\lambda_{H}\left(z_{1}\right)>\lambda_{R}$, then $v$ will jump on a saddle path that leads to a Core-Periphery outcome. There is no ambiguity about which long run spatial configuration will emerge, it all depends on the value of $\lambda_{H}\left(z_{1}\right)$. Only history matters

\footnotetext{
${ }^{14}$ For the analysis of these three representative cases in a model without public debt see Baldwin (2001).
} 
for large migration costs. In this case, the dynamics of perfect foresight is qualitatively equivalent to the dynamics of rational expectations with imperfect information. Thus, all propositions in the paper remain valid.

(2) Intermediate migration cost. In this case there is overlap of saddle paths in a neighbourhood of $\lambda_{L}$ and in a neighbourhood of $\lambda_{R}$. The neighbourhoods in which there is overlap of saddle paths are known as the "regions of overlap” (Krugman, 1991b). If $\lambda_{H}\left(z_{1}\right)$ is in anyone of these regions, then the long run equilibrium will be $\lambda_{C}$ or the Core-Periphery outcome depending on which saddle path is chosen. Instead, if $\lambda_{H}\left(z_{1}\right)$ is outside these regions, then the long run equilibrium will be $\lambda_{C}$ if $\lambda_{H}\left(z_{1}\right) \in\left(\lambda_{L}, \lambda_{R}\right)$ while it will be the Core-Periphery outcome if $\lambda_{H}\left(z_{1}\right)<\lambda_{L}$ or $\lambda_{H}\left(z_{1}\right)>\lambda_{R}$. The overlap of saddle paths generates indeterminacy because the same “initial condition” $\lambda_{H}\left(z_{1}\right)$ may lead to either one of two possible long run spatial configurations. Both history and expectations matters in the case of intermediate migration costs. Outside the overlap regions all the results of the paper apply unchanged. In the overlap regions there is indeterminacy, but this does not invalidate the propositions in the paper, it only implies that the "break point debt divergence" and the "break point debt convergence" become smaller.

(3) Small migration cost. The same indeterminacy as in case (2) emerges with the difference that the regions of overlap cover the entire set $(0,1)$. Therefore, regardless of $\lambda_{H}\left(z_{1}\right)$, any one of the long run equilibria may be reached. In terms of the implications for the results of the paper this is a limit case for it implies that any debt policy (as well as any tax or subsidy policy) is destabilising. 


\section{REFERENCES}

Andersson Fredrik and Rikard Forslid (2003) "Tax competition and economic geography” Journal of Public Economic Theory 5 (2): 279-304.

Baldwin, Richard, E. (2001). “The Core-Periphery model with forward-looking expectations”, Regional Sciences and Urban Economics 31: 21-49.

Baldwin, Richard E. and Krugman, Paul (2004) “Agglomeration, Integration and Tax Harmonisation”. European Economic Review 48(1): 1-23.

Baldwin, Richard, Rikard Forslid, Philippe Martin, Gianmarco Ottaviano, and Frederic Robert-Nicoud (2003) "Economic Geography and Public Policy” Princeton University Press.

Brülhart, M., M. Jametti, and K. Schmidheiny (2012) “Do Agglomeration Economies Reduce the Sensitivity of Firm Location to Tax Differentials?” Economic Journal (articles in press).

Brülhart, Marius, and Federico Trionfetti (2004) "Public Expenditure, International Specialisation and Agglomeration” European Economic Review 48(4): 851991.

Daly, George, G. (1969). “The burden of the debt and future generations in local finance” Southern Economic Journal 36: 44-51.

Forslid, Rikard, and Ottaviano Gianmarco, I. P. (2003) “An Analytically Solvable Core-Periphery Model”, Journal of Economic Geography 3: 229-240.

Judd Kenneth L, (1998) Numerical Methods in Economics, MIT Press, USA.

Kind, Hans Jerle, Karen Helene Midelfart-Knarvik, and Guttorm Schjelderup (2000) “Competing for capital in a 'lumpy’ world”, Journal of Public Economics 78, 253-274. 
Krugman, Paul (1991a). "Increasing returns and economic geography." Journal of Political Economy 99 (3), 483-499.

Krugman, Paul (1991b). “History versus expectations.” Quarterly Journal of Economics 106 (2) 651-667.

Ludema, Rodney D. and Wooton, Ian (2000) “Economic Geography and the Fiscal Effects of Regional Integration”. Journal of International Economics, 52: 331-57. Oates, Wallace. E. (1972) Fiscal Federalism. New York: Harcourt Brace Javanovich.

Ottaviano, Gianmarco, I. P. (2001) “Monopolistic competition, trade, and endogenous spatial fluctuations”. Regional Sciences and Urban Economics 31: 51-57.

Ricardo, David (1817) “On the Principles of Political Economy and Taxation” London, J. Murray, $1^{\text {st }}$ ed.; reprinted as Vol. 1 of The Works and Correspondence of David Ricardo”, P. Sraffa ed., Cambridge University Press, 1951.

Robert-Nicoud, Frédéric (2005), “The structure of simple 'New Economic Geography’ models (or, On identical twins)” Journal of Economic Geography 5: $201-234$.

Shields Gali M. and Michael P. Shields (1989) “The emergence of migration theory and a suggested new direction” Journal of Economic Surveys 3: 277-304.

Trionfetti, Federico (2001) "Public Procurement, Market Integration and Income Inequalities", Review of International Economics (2001) 9 (1): 29-41.

Wellisch, Dietmar, and Wolfram, F. Richter (1995) Internalizing intergenerational externalities by regionalization” Regional Sciences and Urban Economics 25: 685704. 